\title{
Patent ductus arteriosus obscured by a giant aortic aneurysm in a young man with acute heart failure
}

\author{
Krzysztof Jaworski ${ }^{1 *}$, Ilona Michałowska ${ }^{2^{*}}$, Miłosz Marona ${ }^{3}$, Radosław Pracoń4, Eugeniusz Szpakowski ${ }^{5}$, \\ Rafał Dąbrowski ${ }^{1}$
}

'Department of Coronary Artery Disease and Cardiac Rehabilitation, National Institute of Cardiology, Warszawa, Poland

2Department of Radiology, National Institute of Cardiology, Warszawa, Poland

${ }^{3}$ Department of Intensive Cardiac Therapy, National Institute of Cardiology, Warszawa, Poland

${ }^{4}$ Department of Coronary and Structural Heart Diseases, National Institute of Cardiology, Warszawa, Poland

${ }^{5}$ Department of Cardiac Surgery and Transplantology, National Institute of Cardiology, Warszawa, Poland

*Both authors equally contributed to the study

Correspondence to:

Krzysztof Jaworski, MD,

Department of Coronary

Artery Disease and Cardiac

Rehabilitation,

National Institute of Cardiology,

Alpejska 42, 04-628 Warszawa,

Poland,

phone: +48223434259,

e-mail: kjaworski@ikard.pl

Copyright by the Author(s), 2022

DOI: 10.33963/KP.a2021.0187

Received:

September 28, 2021

Accepted:

December 19, 2021

Early publication date: December 22, 2021
A 32-year-old man without previous history of cardiovascular diseases was admitted to the intensive care unit due to acute heart failure. The patient complained of severe dyspnea which had lasted for two days. He denied chest pain, palpitations, and syncope. Blood pressure was 134/52 mm Hg. An electrocardiogram showed sinus tachycardia with a heart rate of $140 \mathrm{bpm}$ and an incomplete left bundle branch block. The concentrations of troponin T (365 ng/l, normal <14 ng/l) and $\mathrm{N}$-terminal pro-brain natriuretic peptide (>30 000 pg/ml, normal <125 pg/ml) were significantly increased. Markers of kidney and liver injury were also elevated (creatinine $1.76 \mathrm{mg} / \mathrm{dl}$; total bilirubin $3 \mathrm{mg} / \mathrm{dl}$; alanine aminotransferase $151 \mathrm{U} /$; international normalized ratio 1.8). Due to the development of pulmonary edema, the patient required mechanical ventilation and infusion of dobutamine and nitroglycerin. Transthoracic echocardiogram (TTE) revealed an enlarged, hypokinetic left ventricle (end-diastolic dimension $92 \mathrm{~mm}$, ejection fraction [EF], 33\%), giant ascending aortic aneurysm, and severe regurgitation of the aortic valve that seemed to be bicuspid (Figure 1A; Supplementary material, Videos $S 1$ and S2). The maximum diameter of the aorta measured on computed tomography (CT) was 105 mm (Figure 1B). Neither dissection nor additional anomalies were detected (Figure 1C). The patient underwent Bentall procedure including implantation of St. Jude Medical $31 \mathrm{~mm}$ prosthesis. The surgeon described the valve as unicommissural with one true commissure between the left and non-coronary cusps. Pre-discharge TTE showed unexpectedly continuous flow between the aorta and the pulmonary artery at the site typical for patent ductus arteriosus (PDA) (Figure 1D; Supplementary material, Video S3). Subsequent CT confirmed the diagnosis of PDA, which had a length of $13 \mathrm{~mm}$ and a diameter of $5 \mathrm{~mm}$ at the junction to the left pulmonary artery (Figure 1E, F). Reanalysis of the initial CT study ensured us that no communication between the aorta and pulmonary artery had been overlooked at that time. Due to the accumulation of fluid in the pericardial cavity with features of imminent cardiac tamponade, the patient needed pericardiocentesis and after rehabilitation, he was discharged home. Three months later the patient was feeling well, a modest improvement of left ventricular function was evident (EF about 38\%). Cardiac catheterization revealed normal pulmonary artery pressure (mean $18 \mathrm{~mm} \mathrm{Hg}$ ). Although the left ventricular dilation had resulted most probably from the aortic regurgitation, PDA could not have been excluded as an additional factor preventing complete recovery of the left ventricular function. Therefore, the Heart Team decided to recommend the percutaneous closure of PDA for this patient. The procedure was performed with Amplatzer Duct Occluder $8 / 6 \mathrm{~mm}$.

In the adult population, PDA is very rarely encountered. The key diagnostic method 

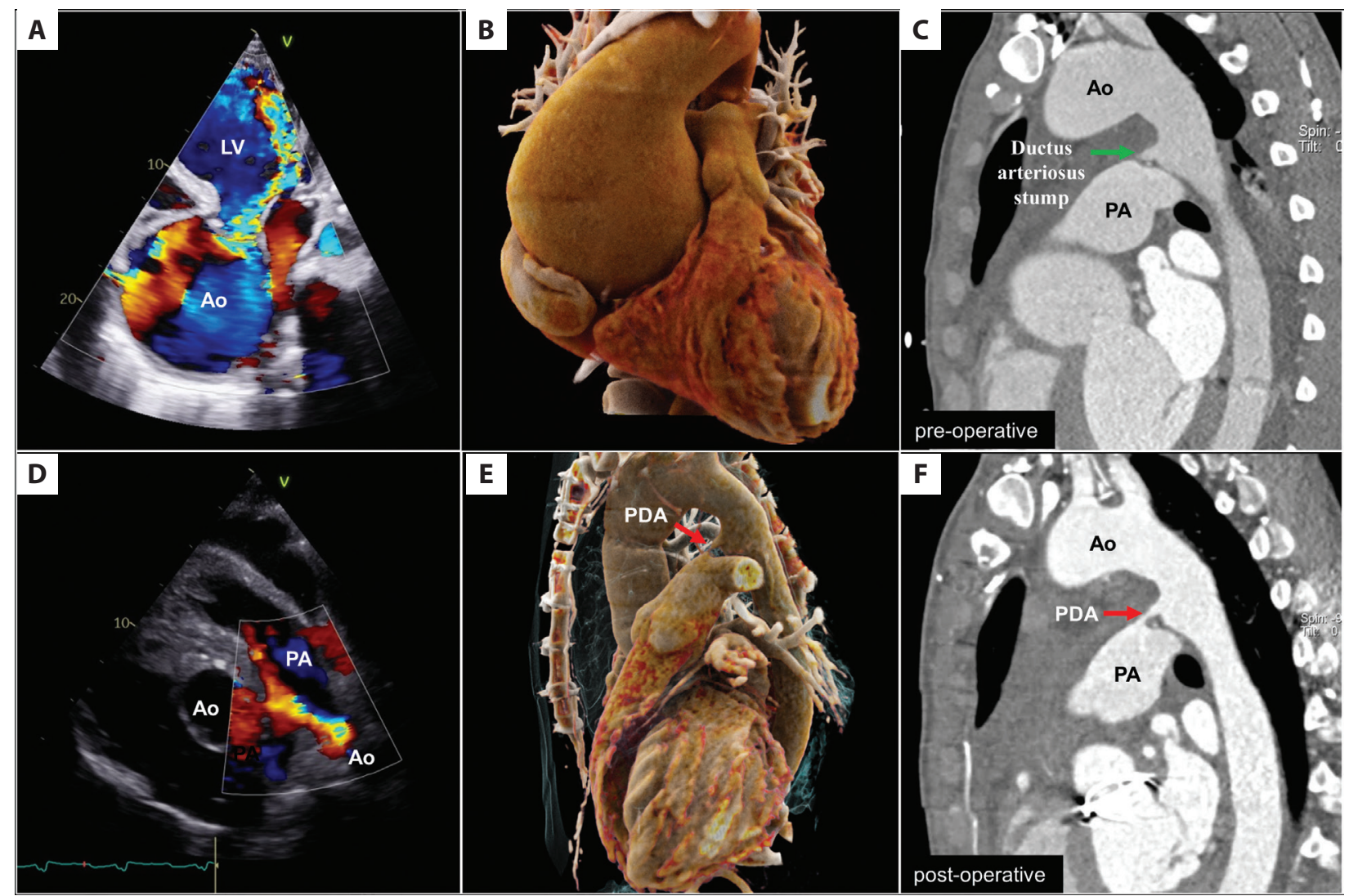

Figure 1A. Transthoracic echocardiogram (TTE), five-chamber view, shows severe aortic regurgitation and ascending aortic aneurysm. B. Computed tomography (CT), volume rendering, presents giant aortic aneurysm. C. Pre-operative CT angiography shows no connection between the aorta and the pulmonary artery, only ductus arteriosus stump (the green arrow). D. Postoperative TTE, parasternal short-axis view, demonstrates flow via patent ductus arteriosus (PDA) between the descending aorta and the left pulmonary artery. E. Postoperative $\mathrm{CT}$, volume rendering, presents the aortic graft and PDA (the red arrow). F. CT angiography shows PDA (the red arrow)

Abbreviations: Ao, aorta; LV, left ventricle; PA, pulmonary artery; PDA, patent ductus arteriosus

is echocardiography, while $\mathrm{CT}$ and magnetic resonance provide a better evaluation of anatomy [1, 2]. However, blood flow via PDA may be diminished in particular circumstances affecting the sensitivity of imaging. In the presented patient, ductus arteriosus was initially visible only in the proximal part, probably as a result of increased pressure in the mediastinum related to the giant aortic aneurysm. Reconstitution of flow occurred after the change in local anatomical and hemodynamic conditions caused by surgery. This emphasizes the role of comprehensive assessment both before and after an operation.

\section{Article information}

Conflict of interest: RP received a research grant agreement and honoraria for lectures from Abbott. All other authors declare no conflict of interest.

Open access: This article is available in open access under Creative Common Attribution-Non-Commercial-No Derivatives 4.0 International (CC BY-NC-ND 4.0) license, allowing to download articles and share them with others as long as they credit the authors and the publisher, but without permission to change them in any way or use them commercially. For commercial use, please contact the journal office at kardiologiapolska@ptkardio.pl.

\section{REFERENCES}

1. Baumgartner H, De Backer J, Baumgartner H, et al. 2020 ESC Guidelines for the management of adult congenital heart disease. Eur Heart J.2021;42(6): 563-645, doi: 10.1093/eurheartj/ehaa554, indexed in Pubmed: 32860028.

2. Schneider D, Moore J. Patent Ductus Arteriosus. Circulation. 2006; 114(17): 1873-1882, doi: 10.1161/circulationaha.105.592063. 